\title{
Sitagliptin Monoterapisi ile Kombinasyon Tedavilerinin Karşılaştırılması
}

\author{
Özen ÖZ GÜL ${ }^{1}$, Pınar ȘișMAN ${ }^{2}$, Soner CANDER ${ }^{1}$, Canan ERSOY ${ }^{1}$
}

1 Bursa Uludağ Üniversitesi Tıp Fakültesi, Endokrinoloji ve Metabolizma Hastalıkları Bilim Dalı, Bursa.

2 Bursa Medicana Hastanesi, Endokrinoloji ve Metabolizma Kliniği, Bursa.

\section{ÖZET}

Çalışmamızda sitagliptinin monoterapide ve kombinasyon (metformin veya pioglitazon) tedavilerinde kullanımlarının glisemik kontrol, lipid profili ve insülin direnci üzerine etkilerinin karşılaştırılması amaçlanmıştır. Yeni tanı almış ve daha önce antidiyabetik tedavi almamış olan toplam 46 tip 2 diyabetik hasta çalışmaya dahil edildi. Hastalara rastgele olarak sitagliptin (grup 1), sitagliptin+metformin (grup 2), sitagliptin+pioglitazon (grup 3) tedavileri başlandı. Tedavide sitagliptin $100 \mathrm{mg} /$ gün, metformin $2000 \mathrm{mg} /$ gün ve pioglitazon $30 \mathrm{mg} /$ gün dozlarında kullanıldı. Altı aylık izlem süresini tüm hastalar tamamladı. Hastalar başlangıçta ve çalışma sonunda antropometrik ölçümler, glisemik parametreler ve lipid düzeyleri açısından değerlendirildi. Hastaların başlangıç antropometrik ölçümleri, glisemik parametreleri ve lipid profilleri benzerdi. Altıncı ay sonunda yapılan değerlendirmede grup 1'de istatistiksel anlamlı vücut kitle indeksi (VKİ) düşüşü gözlenirken, grup 2 ve 3'te istatistiksel anlamlı değişiklik saptanmadı. Hemoglobin A1c her üç grupta da istatistiksel olarak anlamlı düzeyde azaldı, gruplar arasında ise istatistiksel anlamlı farkl11ık saptanmadı. Altıncı ay sonunda serum trigliserid düzeyleri grup 3 'te anlamlı olarak azalırken diğer lipid profili üzerine etkileri açısından her üç grup arasında farklılık saptanmadı. HOMA-IR değerlendirildiğinde 6 ay sonunda grup 1 ve grup 2'de farklılık saptanmazken, grup 3'te anlamlı azalma olduğu görüldü $(\mathrm{p}<0.05)$. Çalışmamız sonucunda sitagliptin monoterapisi sitagliptin+metformin ve sitagliptin+pioglitazon kombinasyon tedavilerinin glisemik değerler ve lipid profili üzerine olan etkileri benzerdi. Sitagliptin pioglitazon kombinasyon tedavisinin insülin direnci ve trigliserid düzeylerini düşürmede daha üstün olduğu saptanmıştır.

Anahtar Kelimeler: Tip 2 diyabet. İnsülin direnci. Sitagliptin. Pioglitazon. Metformin.

Comparison of Sitagliptin Monotherapy with Combination Therapy

\section{ABSTRACT}

The aim of this study was to compare the effects of sitagliptin in monotherapy and combination (metformin or pioglitazone) treatments on glycemic control, lipid profile and insulin resistance. A total of 46 type 2 diabetic patients, who were newly diagnosed and who had not previously received antidiabetic therapy, were included in the study. Patients were randomly assigned to receive sitagliptin (group 1), sitagliptin + metformin (group 2) or sitagliptin + pioglitazone (group 3). Sitagliptin $100 \mathrm{mg} /$ day, metformin $2000 \mathrm{mg} /$ day and pioglitazone 30 $\mathrm{mg}$ /day were used in the treatment. All patients completed the six-month follow-up period. Patients were evaluated at baseline and at the end of the study in terms of anthropometric measurements, glycemic parameters and lipid levels. Initial anthropometric measurements, glycemic parameters and lipid profiles were similar. At the end of the sixth month, a statistically significant decrease in body mass index (BMI) was observed in group 1, while there was no statistically significant difference in group 2 and 3. Hemoglobin A1c was significantly decreased in all three groups and no statistically significant difference was found between the groups. Serum triglyceride levels were significantly decreased in group 3 at the end of the sixth month and no difference was found between the three groups in terms of their effects on the other lipid profile. When HOMA-IR was evaluated, there was no significant difference in group 1 and group 2 at the end of 6 months, whereas there was a significant decrease in group 3 (p <0.05). The effects of sitagliptin monotherapy, sitagliptin+metformin and sitagliptin+pioglitazone combination treatments on glycemic values and lipid profile were similar. Sitagliptin+pioglitazone combination therapy was found to be superior in reducing insulin resistance and triglyceride levels.

Key Words: Type 2 diabetes. Insulin resistance. Sitagliptin. Pioglitazone. Metformin.

Geliş Tarihi: 08 Kasım 2018

Kabul Tarihi: 12 Aralık 2018

Dr. Özen ÖZ GÜL

Bursa Uludağ Üniversitesi Tıp Fakültesi,

Endokrinoloji ve Metabolizma Hastalıkları Bilim Dalı,

Görükle, Bursa.

Tel.: 05322614410

E-posta: drozenoz@gmail.com
Tüm dünyada hızla artan insidansa sahip tip 2 diyabet, mortalite, yaşam kalitesinde azalma ve yüksek sağlık harcamaları gibi pek çok soruna yol açmaktadır. 2030 yılı itibarıyla insidansın tüm dünyada 552 milyona ulaşacağı tahmin edilmektedir ${ }^{1}$. Tip 2 diyabetik hastalarda, insülin direnci ve pankreatik beta hücre fonksiyonlarında ilerleyici kayıp, zamanla hiperglisemiye yol açmakta ve hedeflenen HbA1c değerlerine ulaşmak için kombinasyon tedavilerine gerek duyulmak- 
tadır. Yapılan çalışmalar HbA1c düzeylerindeki her \%1'lik düşüşün diyabete bağlı mikrovasküler komplikasyonları \%35 oranında azalttığını göstermiş$\operatorname{tir}^{2}$. Bu nedenle Amerika Diyabet Cemiyeti (American Diabetes Association- ADA) hastalığın erken evrelerinden itibaren tedavide optimal glisemik kontrolün (HbA1c $<7.0 \%$ ) sağlanmasını önermektedir ${ }^{3}$.

Tip 2 diyabette beta hücre yetmezliği tanıdan önce başlamakta ve tanı anında beta hücre fonksiyonlarında \%80'in üzerinde kayıp gelişmiş olmaktadır. Bu nedenle erken antihiperglisemik tedavi, kalan pankreatik beta hücre fonksiyonların korunması açısından olumlu etkiye sahiptir ${ }^{4}$. Oral antidiyabetik ilaçlar arasında yer alan dipeptil peptidaz-4 (DPP-4) inhibitörleri, etkilerini, glukoz bağımlı insülinotropik polipeptid (Glucose-dependent Insulin releasing Polypeptide- GIP) ve glukagon like peptid-1 (Glucagon-like Peptide 1- GLP-1) gibi biyoaktif peptidleri deaktive eden DPP-4 enzimini inhibe ederek gösterirler. GIP ve GLP-1'nin etkisiyle postprandiyal insülin sekresyonu uyarılır, glukagon sekresyonu baskılanır, gastrik boşalma gecikir ve muhtemel erken doyma sağlanır ${ }^{5}$. DPP-4 inhibitörlerinin pankreas adacık hücreleri üzerinde koruyucu etkilerinin olduğu rapor edilmiştir. Bununla birlikte kardiyovasküler riski azalttıkları düşünülmektedir ${ }^{1}$. Sitagliptin, tek başına kullanıldığında hipoglisemi ve kilo aldırıcı etkisi düşük, iyi tolere edilebilen ve günde tek doz uygulanan bir selektif DPP-4 inhibitörüdür ${ }^{6}$.

Her ne kadar biguanidler ve tiyazolidinedionlar insülin duyarlılaştırıcı ajanlar sınıfında yer alsa da etki mekanizmaları birbirinden farklıdır ${ }^{1}$. Biguanid sınıfında yer alan metforminin majör etkisi glukoneogenezin inhibisyonu yoluyla hepatik glukoz outputunu azaltması ve bunun yanında özellikle öğün sonrası olmak üzere periferal dokularda insülin ilişkili glukoz utilizasyonunu arttırmasıdır. Monoterapide açlık kan glukoz düzeylerinde yaklaşık \%20 oranında ve HbA1c düzeylerinde ise \%1.5'lik düşüş sağlar ${ }^{7}$. Glisemik etkinliği, hipoglisemi ve kilo alımı riskinin düşük olması ve kardiyovaskuler olayları azaltabilmesi nedeniyle tip 2 diyabet tedavisinde en yaygın kullanılan antidiyabetik ilaçtır ${ }^{8}$. Tiazolidinedionlar ise Peroksizom Proliferatör-Aktive Reseptör (Peroxisome ProliferatorActivated Receptor- $\gamma$ - PPAR- $\gamma$ )'lerine bağlanır ve aktive eder. Böylelikle yağ doku, kas ve karaciğerde insülin sensitivitesini arttırarak glukoz utilizasyonunu arttırıcı ve glukoz üretimini azaltıcı etki gösterir. Monoterapide beklenen HbA1c düşüşü \%0.5-1.4'tür' .

Sitagliptin, metformin ve pioglitazon farklı etki mekanizmasina sahip olup, birlikte kullanıldıklarında tedavide tamamlayıcı role sahiptir ${ }^{2}$. Çalışmamızda tip 2 diyabetik hastalarda sitagliptinin monoterapide ve kombinasyon (metformin veya pioglitazon) tedavilerinde kullanımının glisemik kontrol, lipid profili ve insülin direnci üzerine etkilerinin karşılaştırılması amaçlanmıştır.

\section{Gereç ve Yöntem}

Hastalar: Çalışmamız merkezimiz Tıbbi Araştırmalar Etik Kurulu'ndan onay ve hastalardan yazılı bilgilendirilmiş onam formu alınarak yapıldı. Çalışmaya, yeni tanı almış ve daha önce antidiyabetik tedavi almamış, 18 yaş üzerinde olan toplam 46 tip 2 diyabetik hasta dahil edildi. Diyabet tanısı için açlık kan şekerinin en az $2 \mathrm{kez} 126 \mathrm{mg} / \mathrm{dl}$ veya üzerinde bulunması, rastgele KŞ ölçümünün $200 \mathrm{mg} / \mathrm{dl}$ veya üzerinde olmas1, 75 gr ile yapilan oral glukoz tolerans testinde (OGTT) 2.saat kan şekerinin $200 \mathrm{mg} / \mathrm{dl}$ veya üzerinde olması kriter olarak aranmıştır ${ }^{3}$. Tip 1 diyabet, gestasyonel diyabet ve diğer spesifik diyabet tipleri sınıfına dahil olan ve daha önce oral antidiyabetik ilaç ya da insülin kullanan hastalar çalışmaya dahil edilmemiştir.

Calıșma protokolü: Çalışmaya dahil edilen tüm hastalara diyet ve yaşam tarzı değişiklikleri ile ilgili eğitimleri verildi ve rastgele olarak 3 gruba ayrıld1. 1. gruba sitagliptin $100 \mathrm{mg} /$ gün, 2. gruba sitagliptin 100 mg/gün + metformin 2000 mg/gün ve 3. gruba sitagliptin $100 \mathrm{mg} /$ gün + pioglitazon $30 \mathrm{mg} /$ gün başland1. Hastalar tedavilerini 6 ay süresince kullandılar ve bütün hastalar çalışmayı tamamladılar. Çalışmamıza dahil edilen tüm hastaların başlangıç vizitinde vücut ağırlığı, boy, vücut kitle indeksi (VKİ), bel çevresi, kalça çevresi, bel-kalça oranı, yağ oranı ölçümleri yapıldı. VKİ kilogram cinsinden vücut ağırlığının metre cinsinden boyun karesine oranı ile hesaplandı. Bel, kalça ölçümleri elastik olmayan bir mezura ile hastalar ayakta dik pozisyonda iken yapıldı. Bel çevresi, arkus kostaryum ile prosessus spina iliaca anterior süperior arasındaki en dar çaptan, kalça çevresi kalçanın en geniş olduğu çaptan ölçüldü. Vücut yağ oran1-yüzdesi günlük kalibre edilen Tanita aleti ile ölçüldü ve kaydedildi (Tanita, Body Fat Monitor, Tanita Corporation, Tokyo, Japan). Tüm hastaların kan basıncı ve nabız ölçümleri yapıldı. Laboratuvar değerlendirmesinde serum açlık kan şekeri (AKŞ), tokluk kan şekeri (TKŞ), HbA1c, üre, kreatinin, AST, ALT, total kolesterol (TK), HDL-kolesterol (HDL-K), LDL-kolesterol (LDL-K), trigliserid (TG), insülin ve HOMA-IR ölçümleri yapıldı. Hastaların 6. ayın sonunda yapılan değerlendirmesinde, başlangıçta yapılan tüm antropometrik ve biyokimyasal ölçümler tekrarlandi.

Istatistiksel Yöntem: Hastaların antropometrik ve klinik özelliklerini gösteren değişkenler için frekans değerleri ve/veya tanımlayıcı istatistikler hesaplanmıştır. Değişkenlik ölçüsü ise ortalama \pm standart sapma şeklinde verilmiştir. Shapiro-Wilk testi ile sürekli değişkenlerin normal dağılım varsayımlarına uygun olup olmadığı belirlenmiştir. Gruplar arası değerlendirmelerde üç grup için Kruskal Wallis ve ikili karş1laştırmalar Mann-Whitney $U$ testi ile yapılmıştır. Tedavi öncesi ve sonrası bağımlı değişken analizlerinde non-parametrik testler kullanılmıştır. Verilerin 


\section{Sitagliptin Monoterapi ve Kombinasyon Tedavileri}

analizlerinde IBM SPSS versiyon 20 (IBM Acquires SPSS Inc., Somers, NY, USA) programı kullanılmıştır. Tüm istatistiksel analizlerde $\mathrm{p}<0.05$ değeri sonuçlar için istatistiksel olarak anlamlı kabul edilmiştir.

\section{Bulgular}

Çalıșmamıza yeni tanı diyabetik toplam 46 hasta dahil edildi. Çalışmamıza dahil edilen hastaların ortalama yaşı 53.8 \pm 8.1 y1l idi. Sitagliptin monoterapisi alan hasta grubunda (Grup I) 16 hasta, sitagliptin metformin kombinasyon tedavisi alan hasta grubunda (Grup II) 14 hasta ve sitagliptin pioglitazon kombinasyon tedavisi alan hasta grubunda (Grup III) 16 hasta mevcuttu. Hastaların başlangıç antropometrik ölçümleri, glisemik parametreleri ve lipid profilleri benzerdi. Hastaların başlangıç demografik verileri tablo I'de verilmiştir.

Tablo I. Hastaların başlangıç demografik ve laboratuar değerleri

\begin{tabular}{|l|l|l|l|l|}
\hline & \multicolumn{1}{|c|}{$\begin{array}{c}\text { Grup 1 } \\
(\mathrm{n}=16)\end{array}$} & \multicolumn{1}{|c|}{$\begin{array}{c}\text { Grup 2 } \\
(\mathrm{n}=14)\end{array}$} & \multicolumn{1}{|c|}{$\begin{array}{c}\text { Grup 3 } \\
(\mathrm{n}=16)\end{array}$} & $p$ \\
\hline Yaş (yıl) & $55.1 \pm 7.3$ & $53.0 \pm 9.6$ & $53.3 \pm 7.8$ & AD \\
\hline VKi $\left(\mathrm{kg} / \mathrm{m}^{2}\right)$ & $33.1 \pm 5.6$ & $31.5 \pm 5.0$ & $32.3 \pm 3.8$ & AD \\
\hline Bel çevresi (cm) & $109.9 \pm 11.5$ & $106.5 \pm 11.1$ & $107.1 \pm 7.6$ & AD \\
\hline Yağ oranı (\%) & $36.1 \pm 9.0$ & $30.9 \pm 11.7$ & $35.9 \pm 8.5$ & AD \\
\hline AKŞ (mg/dL) & $139.8 \pm 21.4$ & $167.0 \pm 48.0$ & $159.5 \pm 42.1$ & AD \\
\hline TKŞ (mg/dL) & $209.3 \pm 55.8$ & $282.1 \pm 110.8$ & $232.6 \pm 79.2$ & AD \\
\hline HbA1c (\%) & $7.5 \pm 0.9$ & $8.1 \pm 0.8$ & $8.2 \pm 1.3$ & AD \\
\hline TK (mg/dL) & $207.9 \pm 37.5$ & $203.5 \pm 38.0$ & $216.8 \pm 44.8$ & AD \\
\hline LDL-K (mg/dL) & $133.2 \pm 30.1$ & $128.7 \pm 34.3$ & $132.3 \pm 39.0$ & AD \\
\hline HDL-K (mg/dL) & $45.4 \pm 11.7$ & $42.5 \pm 7.1$ & $50.8 \pm 8.2$ & AD \\
\hline TG (mg/dL) & $144.7 \pm 60.0$ & $160.0 \pm 56.7$ & $160.2 \pm 69.2$ & AD \\
\hline Innsülin (mlU/L) & $12.0 \pm 5.4$ & $16.5 \pm 10.1$ & $16.5 \pm 13.7$ & AD \\
\hline HOMA-IR & $4.1 \pm 1.9$ & $7.4 \pm 6.1$ & $6.3 \pm 5.1$ & AD \\
\hline
\end{tabular}

AD: İstatistiksel olarak anlamlı değil, VKİ: Vücut kitle indeksi, AKŞ: Açlık kan şekeri, TKŞ: Tokluk kan şekeri, HbA1c: Hemoglobulin A1c, TK: Total kolesterol, LDL-K: LDL-kolesterol, HDL-K HDL-kolesterol, TG: Trigliserid, HOMA-IR: Homeostatic Model Assessment for Insulin Resistance.
Hastalar 6 ay süresince takip edildi ve 6 . ay sonunda antropometrik ve laboratuar ölçümleri tekrarland1 (Tablo II). Hastaların 6.ay sonunda başlangıca göre antropometrik ve laboratuar ölçümlerinin yüzde değişimleri hesaplandı. Yüzde değişimleri açısından gruplar arasında farklılık görülmedi. Altıncı ay sonunda yapılan değerlendirmede grup 1 ve grup 2'de VKI'de azalma gözlenirken, grup 3'te ise VKI'nde artış saptand1. VKİ ile orantılı olarak grup 1'de bel çevresinde anlamlı azalma mevcuttu ( $\mathrm{p}=0.005)$. Bununla birlikte her üç grupta yağ yüzdesinde istatistiksel olarak anlamlı değişiklik saptanmadı.

Hastaların glisemik parametrelerine bakıldığında AKŞ'nde sadece grup 3'te anlamlı azalma, TKŞ ve HbA1c'de ise tüm gruplarda anlamlı düşüş mevcuttu (Tablo II). Hastaların lipid profilleri değerlendirildirildiğinde tüm gruplarda TK ve LDL-K düzeylerinde istatistiksel anlamlı olmayan azalma, HDL düzeylerinde artma mevcuttu. TG düzeylerindeki düşüş sadece grup 3'de istatistiksel olarak anlamlı idi. HOMA-IR seviyesinin grup 3'te istatistiksel olarak anlamlı azalmış olduğu gözlendi $(\mathrm{p}=0.004)$.

\section{Tartışma}

Sitagliptin potent bir DPP-4 inhibitörüdür. Tip 2 diyabetik hastalarda plazma DPP-4 aktivitesini \%80'den fazla inhibe eder. Böylelikle aktif GLP-1 ve GIP düzeylerinde 2-3 kat artış sağlar. Aschner ve ark.nın yaptıkları çalışmada 741 hasta çalışmaya dahil edilmiş ve sitagliptin $100 \mathrm{mg} / \mathrm{gün}$ doz tedavi ile HbA1c düzeylerinde ortalama $\% 0.79$ ve AKȘ düzeylerinde 17.1 $\mathrm{mg} / \mathrm{dl}$ düşüş sağlanmıştır ${ }^{9}$. Çalışmamızda sitagliptin monoterapisi alan hastalarda 6 . ayın sonunda ortalama $2.5 \mathrm{~kg}$ kilo kaybı gözlendi. VKİ ve bel çevresinde istatistiksel olarak anlamlı azalma mevcuttu. Serum HbA1c'de \%0.92, serum AKȘ düzeylerinde ortalama $5.8 \mathrm{mg} / \mathrm{dl}$ ve TKŞ düzeylerinde $47.3 \mathrm{mg} / \mathrm{dl}$ düşüş

Tablo II. Hastaların başlangıç ve 6. ay demografik ve laboratuar değerlerinin karşılaştırılması

\begin{tabular}{|c|c|c|c|c|c|c|c|c|c|}
\hline & \multicolumn{3}{|c|}{ Grup 1 (n:16) } & \multicolumn{3}{|c|}{ Grup 2 (n:14) } & \multicolumn{3}{|c|}{ Grup 3 (n:16) } \\
\hline & Başlangıç & 6. ay & $p$ & Başlangıç & 6. ay & $\mathrm{p}$ & Başlangıç & 6. ay & $\mathrm{p}$ \\
\hline VKi (kg/m²) & $33.1 \pm 5.6$ & $32.2 \pm 5.5$ & 0.020 & $31.5 \pm 5.0$ & $31.3 \pm 6.0$ & $A D$ & $32.3 \pm 3.8$ & $32.7 \pm 3.7$ & $A D$ \\
\hline Bel çevresi $(\mathrm{cm})$ & $109.9 \pm 11.5$ & $104.7 \pm 9.0$ & 0.005 & $106.5 \pm 11.1$ & $104.0 \pm 10.9$ & $A D$ & $107.1 \pm 7.6$ & $106.7 \pm 8.6$ & $A D$ \\
\hline Yağ oranı (\%) & $36.1 \pm 9.0$ & $36.0 \pm 10.0$ & $A D$ & $30.9 \pm 11.7$ & $30.9 \pm 11.7$ & $A D$ & $35.9 \pm 8.5$ & $35.9 \pm 8.1$ & $A D$ \\
\hline AKŞ (mg/dL) & $139.8 \pm 21.4$ & $134.0 \pm 36.4$ & $A D$ & $167.0 \pm 48.0$ & $135.4 \pm 26.0$ & $A D$ & $159.5 \pm 42.1$ & $116.1 \pm 27.0$ & 0.001 \\
\hline TKŞ (mg/dL) & $209.3 \pm 55.8$ & $162.0 \pm 62.8$ & 0.023 & $282.1 \pm 110.8$ & $196.1 \pm 60.6$ & 0.011 & $232.6 \pm 79.2$ & $162.1 \pm 46.3$ & 0.011 \\
\hline HbA1c (\%) & $7.5 \pm 0.9$ & $6.6 \pm 0.8$ & 0.002 & $8.1 \pm 0.8$ & $7.0 \pm 0.9$ & 0.004 & $8.2 \pm 1.3$ & $6.7 \pm 0.8$ & 0.001 \\
\hline TK (mg/dL) & $207.9 \pm 37.5$ & $195.1 \pm 30.9$ & $A D$ & $203.5 \pm 38.0$ & $192.3 \pm 43.8$ & $A D$ & $216.8 \pm 44.8$ & $212.2 \pm 38.8$ & $A D$ \\
\hline LDL (mg/dL) & $133.2 \pm 30.1$ & $118.4 \pm 26.1$ & $A D$ & $128.7 \pm 34.3$ & $120.0 \pm 26.6$ & $A D$ & $132.3 \pm 39.0$ & $134.7 \pm 35.4$ & $A D$ \\
\hline HDL (mg/dL) & $45.4 \pm 11.7$ & $47.1 \pm 12.9$ & $A D$ & $42.5 \pm 7.1$ & $44.5 \pm 5.3$ & $A D$ & $50.8 \pm 8.2$ & $53.8 \pm 9.1$ & $A D$ \\
\hline TG (mg/dL) & $144.7 \pm 60.0$ & $148.5 \pm 58.4$ & $A D$ & $160.0 \pm 56.7$ & $146.0 \pm 66.0$ & $A D$ & $160.2 \pm 69.2$ & $117.6 \pm 56.8$ & 0.013 \\
\hline İnsülin (mIU/L) & $12.0 \pm 5.4$ & $18.8 \pm 14.6$ & 0.044 & $16.5 \pm 10.1$ & $13.3 \pm 6.7$ & $A D$ & $16.5 \pm 13.7$ & $8.9 \pm 2.8$ & 0.029 \\
\hline HOMA-IR & $4.1 \pm 1.9$ & $6.7 \pm 5.9$ & $A D$ & $7.4 \pm 6.1$ & $4.6 \pm 2.9$ & $A D$ & $6.3 \pm 5.1$ & $2.6 \pm 1.1$ & 0.004 \\
\hline
\end{tabular}

AD: İstatistiksel olarak anlamlı değil, VKİ: Vücut kitle indeksi, AKŞ: Açlık kan şekeri, TKŞ: Tokluk kan şekeri, HbA1c: Hemoglobulin A1c, TK: Total kolesterol, LDL-K: LDL-kolesterol, HDL-K: HDL-kolesterol, TG: Trigliserid, HOMA-IR: Homeostatic Model Assessment for Insulin Resistance. 
gözlendi. Serum HbA1c ve TKŞ'ndeki azalma istatistiksel olarak anlamlı idi. Kan basıncı, lipid parametreleri ve insülin direncinde ise istatistiksel anlamlı fark saptanmadi.

Charbonnel ve ark. metformin tedavisi ile yetersiz glisemik kontrol sağlanan 701 tip 2 diyabetik hastada sitagliptinin etkinliğini araştırmış ve 24 . haftada sitagliptin eklenen grupta plaseboya göre istatistiksel anlamlı HbA1c düşüşü gözlemlemişlerdir. Aynı çalışmada hedef HbAlc düzeyine (HbAlc <\%7) ulaşma oranı metformin+sitagliptin grubunda \%47.0 iken metformin+plasebo grubunda \%18.3 saptanmıştır $^{10}$. Çalışmamızda sitagliptin+ metformin kombinasyon tedavisi alan hasta grubunda 6. ay sonunda vücut ağırlığında, AKŞ'de, TKŞ'de ve HbAlc'de azalma gözlendi. Sitagliptin monoterapisi ile sitagliptin metformin kombinasyon tedavisi karşılaştırıldığında iki grup arasında antropometrik, glisemik ve lipid parametreleri açısından istatistiksel anlamlı fark gözlenmedi.

Tip 2 diyabetik 408 hastanın dahil edildiği plasebo kontrollü bir çalışmada $15 \mathrm{mg} /$ gün, $30 \mathrm{mg}$ /gün ve 45 mg/gün pioglitazon monoterapisi HbA1c düzeylerinde \%0.3-0.9 ve açlık kan şeker düzeylerinde 29.6-55.9 $\mathrm{mg} / \mathrm{dl}$ düşüş sağlanmıştır ${ }^{11}$. Bir başka çalışmada, pioglitazon tedavisine eklenen sitagliptin 12 haftada açlık kan glukozu, postprandiyal glukoz ve HbA1c düzeylerinde istatistiksel anlamlı düşüş sağlamıştır ${ }^{12}$. SUCCESS-2 çalışmasında da sülfonilüre tedavisine eklenen sitagliptin alfa glukozidaz inhibitörleri karş1laştırılmış, 12. haftada HbA1c düzeylerindeki düşüş sitagliptin grubunda daha fazla olmuştur ${ }^{13}$. Takihata ve ark. Japon tip 2 diyabetik hastalarda sitagliptin ve pioglitazon tedavisinin etkinliğini karşılaştırdıkları çalışmalarında sitagliptin pioglitazona göre daha etkin saptanmıştır ${ }^{14}$. Jamehorani ve ark. ise metformin ile yeterli glisemik kontrolün sağlanamadığı hastalarda sitagliptin ve pioglitazon tedavi etkinliğini karşılaştırmış, iki grup arasında istatistiksel anlamlı fark saptanmamıştır. $\mathrm{Bu}$ çalışmada yazarlar iki çalışmanın sonuçları arasındaki farklılığın nedenini Japon tip 2 diyabetik hastalarda diğer ırklara göre insülin direncinin daha düşük olabileceği şeklinde yorumlamışlardır ${ }^{2}$. Yapılan çalışmalarda sitagliptin ve pioglitazon kombinasyon tedavisinin genel olarak iyi tolere edildiği ve hipoglisemi riskini arttırmadığı gözlenmiştir. Bu nedenle diyare gibi metformine bağl1 yan etkiler ve sülfonilürenin neden olduğu hipoglisemi varlığında DPP4 inhibitörleri ve pioglitazonun birlikte kullanılabileceği önerilmektedir ${ }^{5}$.

Kilo alımı tiazolidinedion sınıf ilaçların en sık görülen yan etkisidir. Dormandy ve ark. yaptıkları bir çalışmada ortalama 34.5 ay izlem sonrasinda pioglitazon kullanan grupta plaseboya oranla ortalama 4 kg kilo alımı gözlenmiştir ${ }^{15}$. Buna karşılık, bir başka çalışmada DPP-4 inhibitörlerinin kilo üzerindeki nötr etkisi nedeniyle, pioglitazon 30-45 mg/gün tedavisine ekle- nen sitagliptin 100 mg/gün 24 hafta sonunda istatistiksel anlamlı kilo artışına yol açmamıştır ${ }^{16}$. Çalışmamizda sitagliptin+pioglitazon tedavisi alan grupta vücut ağırlığı ve VKİ'nde istatistiksel anlamlı olmayan artış gözlendi. Serum AKŞ'i, TKŞ'i ve HbA1c'de azalma saptanmış olup sonuçlar istatistiksel olarak anlamlı idi. Hastaların 6 ay sonundaki serum insülin düzeyi ve insülin direncinde istatistiksel olarak anlam11 düşüş saptandı. Sitagliptin monoterapisi ve sitagliptin+pioglitazon kombinasyon tedavisi karşılaştırıld1ğında glisemik ve lipid parametreleri arasında istatistiksel anlamlı fark gözlenmezken HOMA-IR düzeyinin sitagliptin+pioglitazon tedavisi alan grupta anlamlı azaldığı gözlendi. Çalışmamızın kısıtlılıkları tek merkez ve hasta sayılarının azlığı idi. Çalışmaya dahil edilen hiçbir hastada ilaç intoleransı ya da ilaca bağlı yan etkiler saptanmadi.

\section{Sonuç}

Çalışmamız sonucunda sitagliptin monoterapisi, sitagliptin metformin ve sitagliptin pioglitazon kombinasyon tedavilerinin glisemik değerler ve lipid profili üzerine olan etkilerinin benzer olduğu görülmüştür. Sitagliptin pioglitazon kombinasyonunun insülin direncini azaltmada, AKŞ'leri ve TG düzeylerini düşürmede daha üstün olduğu gözlenmiştir. Sitagliptin pioglitazon kombinasyon tedavisinin insülin direnci belirgin olan hastalarda tercih edilebileceği düşünülmüştür.

\section{Kaynaklar}

1. Yokoh H, Kobayashi K, Sato Y, et al, on behalf of the SUCCESS Study Group. Eficacy and safety of the dipeptidil peptidase-4 inhibitor sitagliptin compared with alphaglucisidase inhibitör in Japanese patients with type 2 diabetes inadequately controlled on metformin or pioglitazone alone (Study for an Ultimate Combination Therapy to Control Diabetes with sitagliptin-1): A multicenter, randomizes, open-label, non-inferiority trial. J Diabetes Invest. 2015; 6: 182-91.

2. Jameshorani M, Sayari S, Kiahashemi N, Motamed N. Comparative study on adding pioglitazone or sitagliptin to patients with type 2 diabetes mellitus insufficiently controlled with metformin. Open Access Maced J Med Sci. 2017; 5: 955-62.

3. Nathan DM, Buse JB, Davidson MB, et al. American Diabetes Association; European Association for Study of Diabetes. Diabetes Care 2009; 32: 193-203.

4. Abdul-Ghani MA, Puckett C, Triplitt C, et al. Initial combination therapy with metformin, pioglitazone and exenatide is more effective than sequential add-on therapy in subjects with new-onset diabetes. Results from the Efficasy and Durability of Initial Combination Therapy for Type 2 Diabetes (EDICT): a randomized trial. Diabetes Obes Metab 2015; 17: 267-75.

5. Mikhail N. Combination therapy with DPP-4 inhibitors and pioglitazone in type 2 diabetes: theoretical consideration and therapeutic potential. Vasc Health Risk Manag 2008; 4: 1221-7.

6. Raz I, Hanefeld M, Xu L, Caria C, Williams-Herman D, Khatami H, Sitagliptin Study 023 Group. Efficacy and safety of the dipeptidil peptidase-4 inhibitor sitagliptin as monotherapy in 


\section{Sitagliptin Monoterapi ve Kombinasyon Tedavileri}

patients with type 2 diabetes mellitus. Diabetologia 2006; 49: 2564-71.

7. Bailey CJ, Turner RC. Metformin. N Eng J Med 1996; 334: 574-9.

8. UK Prospective Diabetes Study (UKPDS) Group. Effect of intensive blood-glucose control with metformin on complications in overweight patients with type 2 diabetes (UKPDS 34). Lancet 1998; 352: 854-65.

9. Aschner P, Kipnes M, Lunceford JK, Sanchez M, Mickel C, Williaams-Herman DE, Sitagliptin Study 021 Group. Effect of the dipeptidyl peptidase-4 inhibitor sitagliptin as monotherapy on glycemic control in patients with type 2 diabetes. Diabetes Care 2006; 29: 2632-7.

10. Charbonnel B, Karasik A, Liu J, Wu M, Meininger G. Efficacy and safety of the Dipeptidyl Peptidase- 4 inhibitor sitagliptin added to ongoing metformin therapy in patients with type 2 diabetes inadequately controlled with metformin alone. Diabetes Care 2006; 29: 2638-43.

11. Aronoff S, Rosenblatt S, Braitwaite S, Egan JW, Mathisen AL, Schneider RL. Pioglitazoe hydrocloride monotherapy improves glycemik control in the treatment of patients with type 2 diabetes: a 6-month randomized placebo-controlled doșe-response study. The pioglitazone 001 Study Group. Diabetes Care 2000; 23: $1605-11$.

12. Kashiwagi A, Kadowaki T, Tajima N, et al. Sitagliptin added to treatment with ongoing pioglitazone for up to 52 weeks impro-

ves glycemic control in Japanese patients with type 2 diabetes. J Diabetes Investig 2011; 2: 381-90.

13. Kobayashi K, Yokoh H, Sato Y, et al, SUCCESS Study Group. Efficacy and safety of the dipeptidyl peptidase-4 inhibitor sitagliptin compared with $\alpha$-glucosidase inhibitor in Japanese patients with type 2 diabetes inadequately controlled on sulfonylurea alone (SUCCESS-2): a multicenter, randomized, openlabel, non-inferiority trial. Diabetes Obes Metab 2014; 16: 7615.

14. Takihata M, Nakamura A, Tajima K, et al. Comparative study of sitagliptin with pioglitazone in Japanese type 2 diabetic patients: the COMPASS randomized controlled trial. Diabetes Obes Metab 2013; 15: 455-62.

15. Dormandy JA, Charbonnel B, Eckland DJA, et al, PROactive Investigators. Secondary prevention of macrovascular events in patients with type 2 diabetes in the PROactive study ( $\mathrm{P}>\mathrm{R}>$ Ospective piogltAzone Clinical Trial In macrovascular Events): a randomized controlled trial. Lancet 2005; 366: 127989.

16. Rosenstock J, Brazg R, Andryuk PJ, Lu K, Stain P; Sitagliptin Study 019 Group. Efficacy and safety of the dipeptidyl peptidase-4 inhibitor sitagliptin added to ongoing pioglitazone therapy in patients with type 2 diabetes: a 24-week, multicenter, randomised, double-blind, plasebo-controlled, parallel-group study. Clin Ther 2006; 28: 1556-68. 
